\title{
Paradigm Shift in Routing Approaches for High Speed MANET Applications
}

\author{
Sadanand R. Inamdar, Sathish Babu B. and Ravi M. Yadahalli
}

\begin{abstract}
Effective routing protocol in ad hoc networks involves consideration of key factors like latency, mutual interference between on-going communication during route initiation, power consumption and effective re-routing process for unstable topology conditions in presence of node mobility. Recent ad hoc network applications involve quest for a high throughput, robustness and differentiated service awareness in the context of present 3G/4G and future 5G standards. This paper discusses the motivation for routing strategy with paradigm shift to meet the aspiration set forth under high traffic volume applications.
\end{abstract}

Index Terms-Smart Antenna Technology; Cross layer Optimization; Bio-Inspired Algorithms; Routing Protocols; Ad Hoc Networks.

\section{INTRODUCTION}

The advantages of Mobile Ad hoc NETworks (MANETs) like topological flexibility, fault-resilience, self-healing and independence of fixed infrastructure spark off many vision based applications. Apart from traditional military and mission critical emergency crisis management services that involve setting up of instantaneous networks, MANETs are today explored in low cost business environment that involve collaborative computing outside the office environment and game theory applications. Advanced Personal Digital Assistants and Wi-Fi enabled smart phones are used in MANET applications like off-campus conferences, remote control of lighting/temperature sensors and establishment of cooperation in road side vehicles with the purpose of sharing current status of the road [1]. The dynamic Quality of Service (QoS) requirements in emerging multimedia service based applications of MANETs face the problem of communication link breakage due to node mobility. At network layer, mobility of nodes calls for frequent re-routing that increases the routing protocol's overhead and reduces the overall MANETs performance. Though dynamic network topology higher the chances for node to break its link with neighboríng node, at the same time it higher the possibilities of discovering shorter path to its destination in case mobility follows group mobility pattern [2]. In the present scenario that demand high speed transmission and QoS guaranteed multimedia applications, need of designing efficient routing protocols is essential. This paper provides insight into the routing strategy of MANETs and discusses presently offered technological

Published on January 24, 2017.

Sadanand R. Inamdar is with the Research Center, Siddaganga Institute of Technology (SIT), Tumkur, Karnataka, India as Research Scholar. (email: inamdars09@gmail.com).

Sathish Babu B. is with the Dept. of Computer Science and Engineering, SIT, Tumkur, Karnataka, India as Professor.(e-mail: bsbit@gmail.com ).

Ravi M. Yadahalli is with the Dept. of Electronics and Communication Engineering, SGBIT, Belgaum, Karnataka, India as Professor (e-mail: ravimyahadall@gmail.com ). advancements for protocol designers and network developers. The result and discussion section provides some of the results obtained by the various authors during their implementation of routing and other networking algorithms to justify the offered technological advancement as a motivation for paradigm shift in routing approaches for high speed MANET applications.

\section{OBJECtives AND QuAlities of Routing Protocols IN MANETS}

Routing protocols establishes the governing rules and define the set of parameters that indicate how the packets are exchanged between communicating nodes of MANETs. Objectives of routing activity in MANETs are aimed at discovering a feasible optimal route/path between involved sources to their destination nodes. Some of the criteria employed in identifying the new routes for the purpose of efficient data transmission are: minimum hop length, lower power consumption, life time of wireless link, bandwidth constraints, methods of collecting path breakage and subsequent mending strategy etc. Traditional routing protocols of infra-structured networks cannot be applied to MANET directly, because of its several unique characteristics and unavoidable constrains like dynamic topology, bandwidth limited uni-directional wireless channel, variable capacity links and energy limited operations.

Desirable qualitative parameters of MANET routing protocols as identified in RFC 2501 are: distributed operations, loop freedom, security, sleep period operation and unidirectional link support. Some of the qualitative metrics identified for performance analysis of MANETs routing protocols are: delay, end-to-end data throughput, route acquisition time, out of order packets (in percentage) and protocol's efficiency. Some of the networking parameters that should be considered to assess the efficiency of MANET routing protocols are: network size, network connectivity, rate of change topology, capacity of link, traffic patterns, frequency of sleeping nodes and mobility [3]. The mobility parameter is critical and challenging task due to the reason that all the nodes have flexibility to move in and out of confined MANET area without following predefined pattern. To evaluate the performance of routing protocols several theoretical mobility patterns are suggested. Mobility is related to assess how important is the temporal or spatial topology in developing efficient routing protocol.

\section{ClassificAtion OF Routing PROTOCOLS IN MANETS}

In the process of moving packets between nodes, routing protocol in ad hoc networks uses distributed algorithm to produce several loop free paths with minimum possible overhead [4]. In MANETs, three different categories of routing protocols are identified and each of them are 
designed and applied to specific network circumstances. Figure 1 shows the basic classification of the routing protocols in MANETs.

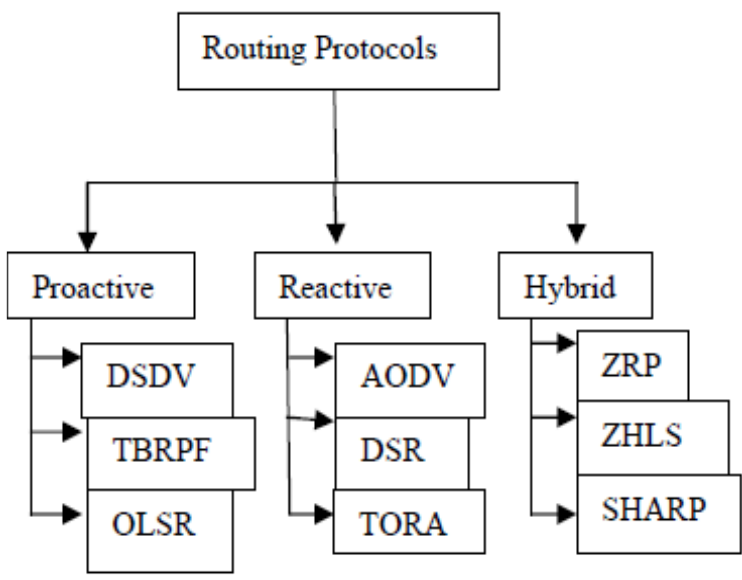

Fig. 1.Classification of Ad hoc Routing Protocols.

Proactive or sometimes called as table driven routing protocols require possessing of consistent/updated routing information from each source unit to every other unit in the given wireless network set up even without requiring it [5]. Routing table(s) maintained at every node of proactive protocols stores complete path information to remaining nodes of the network. To maintain the consistency with change of network topology, updating of routing tables is mandatory. To do this, the network units must broadcast their routing tables periodically without fail. Once nodes succeed in keeping routing information up-to-date then, network unit send messages without any further delay. Proactive protocols are not recommended for large sized MANETs as there is a necessity to maintain node entries for each and every node of network, resulting in large volume of data at the routing table of every unit. Destination Sequenced Distance Vector (DSDV), Topology Broadcast based on Reverse Path Forwarding (TBRPF), Optimized Link State Routing (OLSR), Fisheye State Routing (FSR) and Wireless Routing Protocol (WRP) are dominantly referred proactive routing protocols [6-10].

The route initiation task of reactive routing protocols is triggered only if the node has packet due for transmission. After an optimal path is set between sender node to its final destination node, packet is routed along an identified path. This decrease in redundant/extra information in the form of protocol overhead comes with a delay to sending their messages. The protocols, namely, Ad hoc On Demand Distance Vector (AODV), Dynamic Source Routing (DSR), Temporally-Ordered Routing Algorithm (TORA) and Label based Multipath Routing (LMR) work on the principle of reactive routing approach [11-14].

Other categories of customised routing protocols are also designed in the applications of MANETs called hybrid routing protocols that attempts to combine benefits of proactive and reactive approaches [15-17]. Proactive protocols exhibit less latency and more overhead and while reactive protocols exhibit larger latency and less overhead [18]. Thus a hybrid protocol that trade-off between the shortcomings and benefits of both proactive and reactive routing protocols are designed based on the requirements of applications. The advantages and disadvantages of proactive and reactive are given in table land comparison of some examples of proactive routing protocols and reactive routing protocols are presented in table 2 .

TABLE I: Advantages and disadvantages of proactive and reactive routing protocols.

\begin{tabular}{|l|l|l|}
\hline PROTOCOL & \multicolumn{1}{|c|}{ ADVANTAGES } & \multicolumn{1}{c|}{ DISADVANTAGES } \\
\hline Proactive & $\begin{array}{l}\text { Ready availability of routing } \\
\text { information helps to achieve } \\
\text { lower latency. }\end{array}$ & $\begin{array}{l}\text { To keep routing information } \\
\text { readily available, broadcasting is } \\
\text { done in the whole network that } \\
\text { creates larger overhead. }\end{array}$ \\
\hline Reactive & $\begin{array}{l}\text { Only when needed route } \\
\text { information is generated hence } \\
\text { results in lower overhead. Free } \\
\text { from loops. }\end{array}$ & $\begin{array}{l}\text { Fresh generation of routing } \\
\text { information causes increased } \\
\text { latency. }\end{array}$ \\
\hline Hybrid & $\begin{array}{l}\text { Recommended for larger } \\
\text { networks. Availability of up-to- } \\
\text { date information. }\end{array}$ & More complex. \\
\hline
\end{tabular}

TABLE II: Comparison of proactive and reactive routing protocols.

\begin{tabular}{|l|c|c|c|c|c|c|}
\hline \multicolumn{1}{|c|}{$\begin{array}{c}\text { ROUTING } \\
\text { TYPE and } \\
\text { PARAMITERS }\end{array}$} & \multicolumn{3}{|c|}{ PROACTIVE } & \multicolumn{3}{c|}{ REACTIVE } \\
\cline { 2 - 7 } & DSDV & WRP & OLSR & AODV & DSR & TORA \\
\hline Updating strategy & Periodic & Periodic & Periodic & - & - & - \\
\hline Loop free feature & Yes & Yes & Yes & - & - & - \\
\hline Overhead of routing & High & High & Low & High & High & High \\
\hline No of routing tables & Two & Four & Four & - & - & - \\
\hline Route discovery & - & - & -- & By source & By source & Locally \\
\hline Throughput & Low & Low & Medium & High & Low & Low \\
\hline Periodic update & - & - & -- & No & No & No \\
\hline Performance metric & - & - & -- & Speed & Shortness & Speed \\
\hline Overhead of caching & Medium & High & High & Low & High & Medium \\
\hline
\end{tabular}

Route discovery process of routing protocols in MANETs can be broadly divided into two major components/phases they are:

1. Route discovery: In route discovery phase, source unit starts a process of finding possible path on demand basis. To check for availability of path to destination, source unit verifies its route cache, if a feasible path is not available source unit initiates route discovery process. The information present in source unit includes the details of Internet Protocol(IP) address of destination and intermediate units.

2. Route maintenance: Route maintenance phase in MANETs is faced with node mobility that creates change of network topology and link breakages in the network to result in route failure. To maintain route, reactive protocols use acknowledgement mechanism.

\section{ENABLING TECHNOLOGIES FOR ROUTING IN MANETS}

Though there is plenty of literature material is available to design efficient and optimally balanced routing protocols, a joint design approach that considers the designing of routing protocol in tune with underlying Medium Access Control (MAC) protocol still requires to be investigated. Advantages of Smart antenna at the physical layer can be employed to develop Directional MAC (DMAC) protocol. Efforts of research are now put to jointly optimize the performance of lower three layers using cross layer interaction. This section investigates different enabling technologies related to design and development of effective routing protocols in MANETs that include: smart antenna technology, Cross Layer Design (CLD) approach and Bioinspired algorithms. 


\section{A. Smart antenna technology}

Traditionally, MANETs either use omni-directional antenna against smart antenna or use smart antenna just as add on feature due to cost constraints [19]. MANETs now need to utilize the smart antenna technology features to its fullest potential for satisfying the requirements of present day MANET application users. The limiting factors of Omni-directional enabled MANETs such as limited range of transmission, higher interference area and restricted bandwidth usage have resulted in less spatial re-use. Typical omni-directional antennas employed in conventional MANETs have simple dipole antennas that radiate signals in all directions thus only a small portion of the signal reaches intended receiver that results in effects like, waste of signal energy, serious interference to neighboring nodes, poorer spectral efficiency and reduced frequency re-use. These negative effects combined together results in lower capacity and this has motivated researchers to use of smart antenna technology in MANETs and re-visit routing activity of MANET applications in presence of smart antenna technology for higher gain, interference reduction capability and larger traffic transmission rate support.

Smart antenna technology uses spatial signal separation capable antenna array system wherein it is possible to radiate radio frequency energy towards an intended receiver with very narrow beam width and also nulls are created towards interfering nodes of a MANETs. An antenna array system is able to reduce the co-channel interference and impacts of multipath effects. An antenna system could be controlled in an intelligent way to maximize its performance by using digital signal processing. Smartness of smart antenna lies in its ability to send and receive in specific direction by properly orienting its antenna direction towards intended node and processing of signal digitally. Typical smart antenna is made up of number of antenna elements that are organized to form a special configuration and complex weights are assigned to each element as shown in figure 2 .

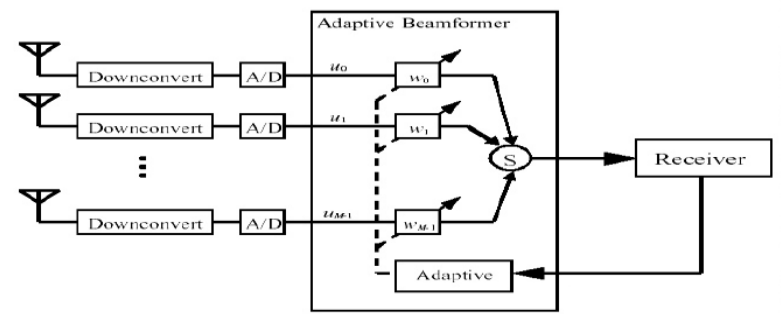

Fig. 2. Smart antenna beamforming.

The beam pattern of this smart antenna array is identified by the weights associated with elements and is augmented with signal processing capability to obtain maximum possible Signal to Interference and Noise Ratio (SINR) of the intended signal. Using pattern controllable smart antennas, it is possible to null out the interference created by other neighboring nodes and get efficient frequency response that help to increase overall system capacity [20]. The pattern of radiation is determined by the features of antenna array that include the geometrical configuration of the array, the count of elements used, the distance between elements and the amplitude plus phase of the input signal applied to each antenna element. Superior transmission /reception and effective interference suppression capabilities of smart antenna technology are used to develop directional routing protocols for recent MANET applications [21-23].

\section{B. CLD approach}

The specific traits of MANETs pose several critical design challenges to develop protocol for its layers. The physical layer's challenge is to identify the instantaneous changes in the link features. The MAC layer that handle fair channel access and packet collision conditions has to deal with hidden node and/or exposed node problems. Dealing with node cooperation to discover and maintain optimal path is required at network layer. Most of protocols proposed for MANETs assume layered architecture design which is highly rigid or strict and each layer specific protocol architecture is only concentrated about the interface to neighboring layers. In recent years, due to availability of CLD technologies the MANET protocols have given importance on establishing significant interactions among various layers of the network stack to enhance network performance [24]. Several functional requirements such as node mobility management, QoS awareness, node's cooperation, energy conservation and security aspects can be effectively implemented by exploiting and combining mechanisms of all the layers of the MANETs. Type of interactions among layers of the network stack depends on information flow among different layers as illustrated in figure 3 .

\begin{tabular}{|c|c|c|c|}
\hline Application Layer & \multirow{5}{*}{\multicolumn{2}{|c|}{ 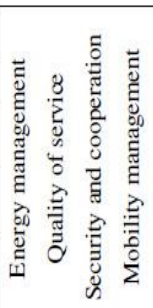 }} & Group Communication, Service Locations \\
\hline Transport Layer & & & Transport Layer Protocols \\
\hline Network Layer & & & TCP/IP routing, Addressing, Forwarding \\
\hline MAC Layer & & & $\begin{array}{l}\text { Framing, Error Detection and Control, } \\
\text { Congestion }\end{array}$ \\
\hline Link Layer & & & $\begin{array}{l}\text { Antennas, MAC, Bluetooth, Power Control, } \\
\text { 802.11, Hyper LAN. }\end{array}$ \\
\hline
\end{tabular}

Fig. 3. MANET functions sharing between different layers through CLD.

This CLD approach that, introduces stack wide layer interdependencies is beneficial in dynamic environments of MANETs. The CLD approach makes use of the current state information available throughout the network stack to develop adaptive protocols. The motivations that favour the necessity of CLD in applications of MANETs are:

1. The necessity of network protocols to be adaptive to network dynamics by adjusting its behavioral parameters according to the present network state.

2. In context aware solutions that uses the metrics influencing the network state like medium status, level of congestion and traffic flow requirements need redesigned protocols that involve interaction between multiple layers.

3. Role of more than one layers is involved to effectively address issues of MANETs like security, energy constraint and topology control.

Some of the drawbacks observed in the cross layer interaction based design include creation of adaptation loops due to interacting protocols and incorrect system implementation due to dependencies caused by non essential functionalities. Several cross layer interaction found in literature and approach followed in [25] suggest the cross layer solution that involves layers like Physical, MAC, Network and Transportation. The existing methods for cross 
layer optimization are normally based on joint solutions which considers three bottom layers of standard ISO reference protocol suite. The basic questions in CLD approach are: which layers of the standard reference architecture are to be considered for cross layer interaction? And how to implement intended interaction between identified layers of standard reference? The reasons for asking these questions are: a comprehensive analysis indicating the benefits and drawbacks that suggest the complexity and achievable performance enhancement are not available. Another issue in CLD approach is to how the cross layer interaction based architecture and traditional layered model based architecture can coexist with one another. Several MANET protocols are developed with the use of cross layer interaction to exchange state information in order to obtain performance gain [26-28].

\section{Bio-inspired algorithms}

Nature in the form of social insects like ants, wasps, bees and termites offer an inspiration to find solution for issues of MANETs. The peculiar behavioral characteristic of MANETs like: i) Locality of interactions, ii) Existence of more than one paths, iii) Self-organization nature, iv) Backup strategy for failure and v) Quick and robust adaptation measures in presence of changing topological and traffic conditions, can be effectively solved by using metaheuristic approach. Many of complex optimization problems are effectively addressed using Swarm Intelligence (SI) which is a sub field of Computational Intelligence. Some of the metaheuristic algorithms like, Ant Colony Optimization (ACO), Particle swarm optimization and Bee Colony Optimization that are based on population based methods, have been extensively studied for analyzing MANETs global behavior which stems from repetitive local interaction of individual agents with each other and their surroundings [29]. Collective behavior of social insect colonies where each individual though act independently of each other produces planned required output. ACO approach which is a prominent and different flavour of SI paradigm emphasizes on bottom up design method for giving better results in protocols of MANETs.

Foraging behavior of real ants when imitated by the artificial ant agents of ACO, high dimension combinatorial optimization problems are solved to greater satisfaction level. Social ants deposit chemical substance called pheromone on the ground when they forage, with the help of this pheromone, indirect communication is established between ants. The operators used in ACO are pheromone trail update and pheromone trail evaporation rate. The number of ants and the count of iteration used in the algorithm are used as control parameters in ACO. MANETs use these operators and control parameters of ACO in designing the algorithms by appropriately replicating the foraging behavior. Routing protocols with reduced end-toend delay and route discovery latency are developed when ant agents of ACO are employed to discover and maintain high connectivity paths in unstable natured MANETs. Even for different node densities, data loads and various nodal mobility ACO algorithm based routing protocols of MANETs are capable of achieving enhanced throughput with lesser routing overhead. Energy awareness is achieved in routing activity with the use of ACO based algorithms helps to increase the life time of MANETs. Bio-inspired routing protocols provide promising alternative (both theoretically and practically) to conventional approaches in finding fault tolerant, QoS aware and globally best route [30-32].

\section{RESUlTS AND DISCUSSIONS}

In hybrid routing intelligent algorithm, combination of ACO and Particle Swarm Optimization (PSO) techniques are used to improve metrics of MANET routing like, communication cost, end-to-end delay and power consumption by Nancharaiah. B. et al in [33]. The route discovered thus has minimum delay, shorter distance, lower cost and power consumption as illustrated in figure 4 and figure 5 .

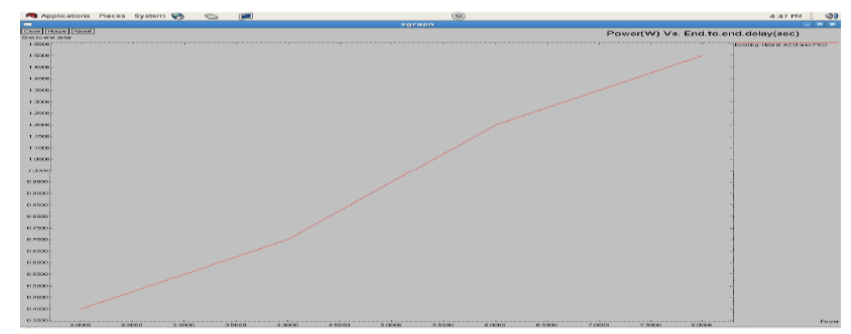

Fig. 4. Power (W) Vs. End to end delay (sec) [Hybrid ACO_PSO].

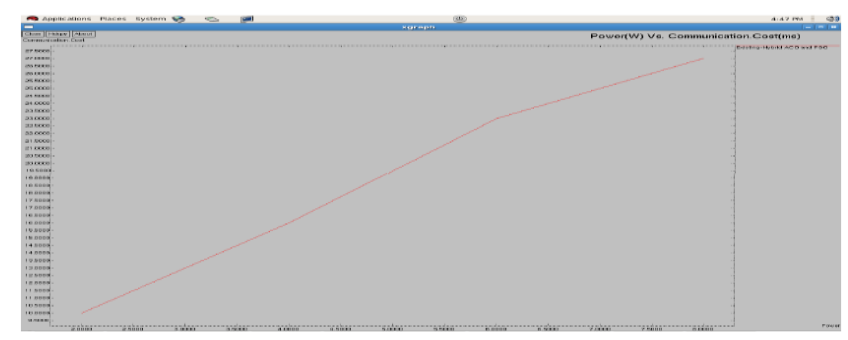

Fig. 5. Power (W) Vs. Communication cost (ms) [Hybrid ACO_PSO].

Decade of research and development in smart technology has helped to overcomes its cost and size barriers. Smart antenna technology is now used for controlling the level of interference in the network, to achieve the increased spectral reuse and efficiency in the ad hoc networking. In [34], Multiple Beam Antenna Array MAC (MBAA-MAC) with smart antenna technology is proposed by Rajesh Verma et al. to demonstrate improved the spatial reuse by establishing concurrent directional transactions. The increase in throughput of MBAA-MAC is as illustrated in figure 6.

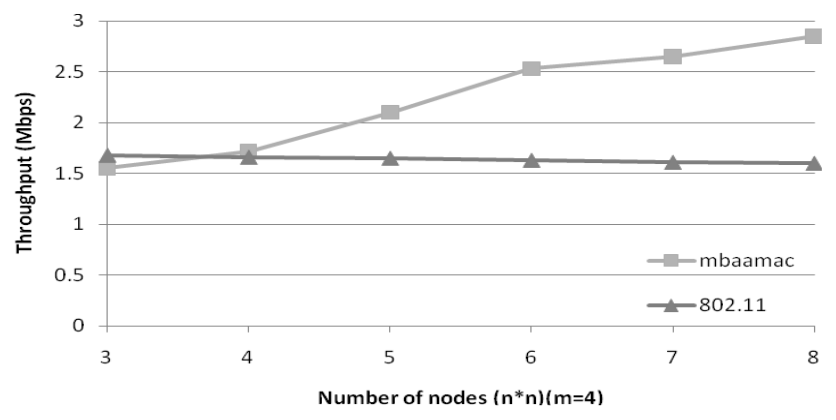

Fig. 6. Performance of the MBAA-MAC and IEEE 802.11 protocols (random grid topology).

Experimental results obtained by Wen Kuang Kuo proves that radically different approach of CLD enables more precise adjustments to network conditions and fluctuation of link parameters [35]. CLD thus ensures energy efficiency of protocols by 7.87 times over the minimum hop count 
routing by reducing the detrimental effects of interference as depicted in figure 7 and as summarized in Table 3.

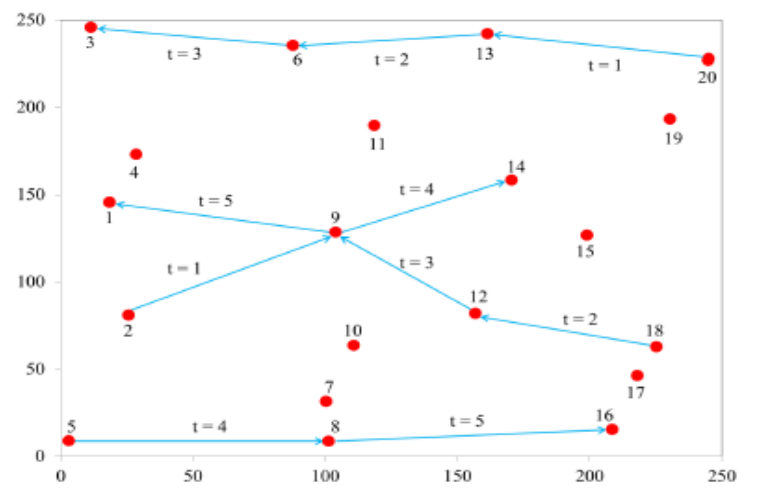

Fig. 7. CLD approach based Routing topology for $\mathrm{T}=5$.

TABLE III: Optimization results of the minimum hop-count routing.

\begin{tabular}{|l|l|l|l|l|}
\hline $\begin{array}{l}\text { Time } \\
\text { slot }\end{array}$ & $\begin{array}{l}\text { Active } \\
\text { link }\end{array}$ & $\begin{array}{l}\text { Transmission } \\
\text { power }(\mathrm{mw})\end{array}$ & $\begin{array}{l}\text { Capacity } \\
\text { (Mbps) }\end{array}$ & $\begin{array}{l}\text { Flow rate } \\
(\mathrm{Mbps})\end{array}$ \\
\hline 1 & $20 \rightarrow 13$ & 1.03 & 7.7 & 7.7 \\
\hline 2 & $13 \rightarrow 3$ & 9.72 & 7.7 & 7.7 \\
\hline 3 & $18 \rightarrow 1$ & 28.29 & 5.45 & 5.45 \\
\hline 4 & $2 \rightarrow 14$ & 36.93 & 12.65 & 12.65 \\
\hline 5 & $5 \rightarrow 16$ & 14.85 & 4.3 & 4.3 \\
\hline
\end{tabular}

This is due to difference in the routing approach followed by the minimum hop-count routing that usually prefers longer distance (strict layering with higher power consumption) for each hop as against CLD based routing that jointly considers routing, traffic scheduling, and power control.

Jianyu Niu et al. have developed the effective medium access strategy at MAC layer, to exploit smart antenna's spatial diversity this enhances the overall capacity of the ad hoc networks [36]. Radiation patterns of adaptive array antenna (that is capable of introducing nulls towards interferer) have resulted in increased network capacity as illustrated in figure 8 .

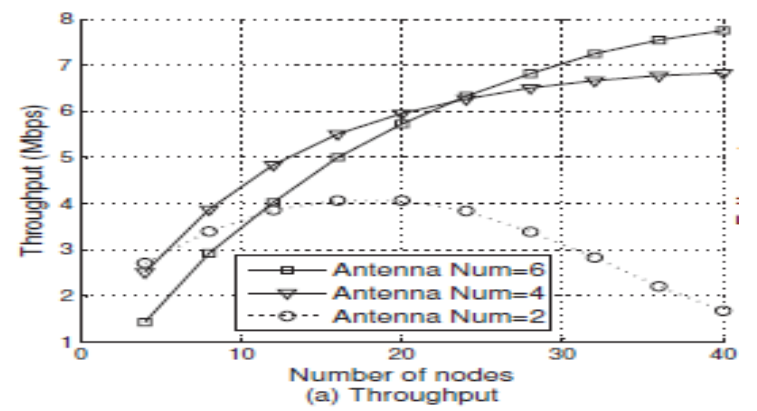

Fig. 8. Network performance with different number of directional nodes.

\section{CONCLUSIONS}

To establish durable routes for multi-hop data exchange in future high speed applications, this paper explores the motivations for use of smart antenna technology CLD approach and bio-inspired algorithms in designing routing protocols for MANETs. The investigation reveals that, routing strategy developed with new paradigm shift has benefit of routing protocols that are able to adapt as per network conditions and support applications with seamless ubiquitous access to distributed resources and service requirements. The protocol's adaptation to present network conditions and utilization of underlying directional communication based medium access methods results in MANET applications which can effectively meet the challenges to be confronted during coming years.

\section{REFERENCES}

[1] Charalampos Kalalas, Linus Thrybom and Jesus Alonso Zarate, "Cellular Communication for Smart Grid Neighborhood Area Networks: A Survey," IEEE Access, Vol. 4, pp. 1469-1493, April, 2016.

[2] X. Hong, M. Gerla, G. Pei and C. Chiang, "A Group Mobility Model for Ad hoc Wireless Networks," in Proc. of ACM International Workshop on Modelling and Simulation of Wireless and Mobile Systems (MSWiM), Vol. 1, pp. 53-60, 1999.

[3] S. Corson and J. Macker, "MANET: Routing Protocol Performance Issues and Evaluation considerations," RFC 2501, IETF Network Working Group, January 1999, [Online] available: http://www.ietf.org/rfc/ rfc2501.txt. Cited 18th Nov. 2016.

[4] D. Satyajeet, A. R. Deshmukh and S. S. Dorle, "Heterogeneous Approaches for Cluster based Routing Protocol in Vehicular Ad Hoc Network (VANET)," International Journal of Computer Applications, Vol. 134, No.12, pp. 1-8, January 2016.

[5] Daxin Tian, Yunpeng Wang, Haiying Xia, and Fengtian Cai, "Clustering multi-hop information dissemination method in vehicular ad hoc networks," Intelligent Transport Systems (IET), Vol. 7, No. 4, pp. 464- 472, December 2013.

[6] C. E. Perkins and P. Bhagwat, "Highly Dynamic DestinationSequenced Distance-Vector (DSDV) for Mobile Computers," in Proc. of ACM Conferences on Communications Architectures, Protocols and applications, London, UK, Vol. 24, Issue 4, pp. 234-244, August 1994.

[7] R. Ogier, M. G. Lewis, F. L. Templin and B. Bellur, "Topology Dissemination Based on Reverse Path Forwarding (TBRPF)", RFC 3684, Network Working Group, Feb 2004, [Online] available: http://www.ietf.org/rfc/ rfc3684.txt. Cited 28th Nov. 2016.

[8] Thomas Heide Clausen, Gitte Hansen, Lars Christensen and Gerd Behrmann, "The Optimized Link-State Routing Protocol Evaluation through Experiments and Simulation," in Proc. of IEEE Symposium on Wireless Personal Mobile Communications, 6 pages, Sept. 2001.

[9] G. Pei, M. Gerla and T.W. Chen, "Fisheye state routing in mobile ad hoc networks," in Proc. of IEEE ICDCS Workshop on Wireless Networks and Mobile Computing, pp. D71-D78. Taipei, Taiwan, April 2000.

[10] Singh Rajeshwar, Singh Dharmendra K. and Kumar Lalan, "Performance Evaluation of DSR and DSDV Routing Protocols for Wireless Ad hoc Networks," International Journal Advanced Networking and Applications, Vol. 02, Issue 04, pp. 732-737, 2011.

[11] C. E. Perkins and E. M. Royer, "Ad-hoc On-Demand Distance Vector (AODV) Routing," in Proc. of. IEEE Workshop on Mobile Computing Systems and Applications (WMCSA-1999), Vol. 1, pp. 90100,1999

[12] D. B. Johnson and D. A. Maltz, "Dynamic Source Routing (DSR) in Ad Hoc Wireless Networks," Mobile Computing, Ch\#5, Kluwer Academic Press, pp. 153-181, 1996.

[13] D. A. Maltz, J. Broch, J. Jetcheva and D. B. Johnson, "The Effects of On Demand Behavior in Routing Protocols for Multi-hop Wireless Ad Hoc Networks," IEEE Journal on Selected Areas in Communications, special issue on Wireless Ad Hoc Networks, Vol. 17, no. 8, pp. 1439-1453, 1999.

[14] Park V. D. and Corson D. S., "A Highly Adaptive Distributed Routing Algorithm for Mobile Wireless Networks," in Proc. of IEEE Conference on Computer Communications (INFOCOM 1997), Vol. 1, pp. 1405-1413, 1997.

[15] Sanku Sinha and Biswaraj sen, "Effect of Varying Node Density and Routing Zone Radius in ZRP: A Simulation Based Approach", in Proc. of International Journal on Computer Science and Engineering (IJCSE), Vol.4, No.6, June 2012.

[16] M. Joa Ng and I. Tai Lu, "A Peer-to-Peer Zone-Based Two Level Link State Routing for Mobile ad Hoc Networks", IEEE on Selected Areas in Communications, Vol. 17, No. 8, pp. 1415-1425, 1999

[17] Rama subramanian, V., Haas, Z. J. and Sirer, E. G., "SHARP: A hybrid adaptive routing protocol for mobile ad hoc networks," in Proc. of the 4th ACM international symposium on Mobile ad hoc networking \& computing, Vol. 1, pp. 303-314, 2003.

[18] L. Anderegg and S. Eidenbenz, "Ad hoc-VCG: A Truthful and CostEfficient Routing Protocol for Mobile Ad hoc Networks with Selfish Agents," in Proc. of ACM International Conference on Mobile 
Computing and Networking (MobiCom 2003), Vol. 1, pp. 245-259, 2003.

[19] Zevallos Luna J., L. Dussopt and A. Siligaris, "Packaged Transceiver with On-Chip Integrated Antenna and Planar Discrete Lens for UWB Millimeter Wave Communication," IEEE International Conference on Ultra-Wideband, pp. 374-378, Paris, France, September 2014.

[20] Tuomas Paso, Juha Pekka Makela and Jari Iinatti, "TDMA Slot Borrowing Scheme Utilizing Smart Antenna in Ad Hoc Networks," Military Communication Conference (MILCOM-2010), pp. 19301935, 2010.

[21] Angeliki Alexiou and Martin Haardt, "Smart antenna technologies for future wireless systems: Trends and challenge," IEEE Communication Magazine Vol. 42, No 9, pp. 90-97, October 2004

[22] S. Wang, M. Liu, X. Cheng, Z. Li, J. Huang and B. Chen, "Opportunistic routing in intermittently connected mobile P2P networks," IEEE Journal on Selected Areas in Communications, Vol. 31, No. 9, pp. 369-378, 2013.

[23] Woongsoo Na, Laihyuk Park and Sungrae Cho, "Deafness-aware MAC (DAMAC) protocol for directional antennas in wireless ad hoc networks," Elsevier, Ad Hoc Networks, Vol.24, pp. 121-134, 2015.

[24] M. Isabel Vara and Celeste Campo, "Cross-Layer Service Discovery Mechanism for OLSRv2 Mobile Ad Hoc Networks," Sensors, Vol. 15, pp. 17621-17648, 2015.

[25] Moltchanov D. and Koucheryavy Y., "Cross-layer modeling of wireless channels: An overview of basic principles," Wireless Personal Communications, Vol. 74, no. 1, pp. 23-44, 2014

[26] Sneha V. Sangolli and Jayavignesh Thyagarajan, "An Efficient Congestion Control Scheme Using Cross-Layered Approach and Comparison of TCP Variants for Mobile Ad-hoc Networks (MANETs), IEEE, First International Conference on Networks \& Soft Computing(ICNSC2014), pp. 30-34, 2014.

[27] Anshu Chaturvedi, D.N. Goswami and Shivjay Singh, "Energy Aware Route Selection Algorithm for Cross Layer Design over MANET' IEEE, Fourth International Conference on Reliability Infocom technologies and Optimization (ICRITO) Trends and Future Directions, pp. 1-6, September 2015.

[28] Wen-Kuang Kuo and Shu-Hsien Chu, "Energy Efficiency Optimization for Mobile Ad Hoc Networks", IEEE Journals and Magazines, Vol. 4, pp. 928-940, 2016.

[29] Jabbarpour, M. R., Malakooti, H., Noor, R. M., Anuar, N. B. and Khamis, N., "Ant colony optimization for vehicle transaction systems: applications and challenges," International Journal of Bio-Inspired Computation, Vol. 6, pp. 32-56, 2014.

[30] Nishitha Taraka and Amarnath Emani, "Routing in Ad Hoc Networks Using Ant Colony Optimization," Fifth International Conference on Intelligent Systems, Modeling and Simulation, Vol. 1, pp. 546-550, 2014.

[31] C. Rajan, K. Geetha, C. Rasi Priya and R. Sasikala, "Investigation on Bio-Inspired Population Based Metaheuristic Algorithms for Optimization Problems in Ad Hoc Networks," International Journal of Mathematical, Computational, Physical, Electrical and Computer Engineering, Vol. 9, No. 3, pp. 163-170, 2015.

[32] Shohei Miyashita and Yamin Li, “ARMPP: An Ant-based Routing Algorithm with Multi-phase Pheromone and Power-saving in Mobile Ad Hoc Networks, IEEE Third International Symposium on Computing and Networking, Vol. 1, pp. 154-160, 2015.

[33] Nancharaiah. B, Chandra Mohan. B, "The performance of a hybrid routing intelligent algorithm in a mobile ad hoc network", Computers and Electrical Engineering, Vol. 1, pp. 1255-1264, 2014.

[34] Rajesh Verma, Arun Prakash, P. K. Verma, Neeraj Tyagi and Rajeev Tripathi, "A Novel MAC Protocol for MANETs using Smart Antenna System," International Conference on Power, Control and Embedded Systems (ICPCES), Vol. 1, pp. 1-6, 2010.

[35] Wen-Kuang Kuo and Shu-Hsien Chu, "Energy Efficiency Optimization for Mobile Ad Hoc Networks," IEEE Access, Vol. 4, pp. 928-940, 2016

[36] Jianyu Niu, Ruonan Zhang, Lin Cai and Jianping Yuan, "A FullyDistributed Directional-to-Directional MAC Protocol for Mobile Ad Hoc Networks," International Conference on Computing, Networking and Communications, Mobile Computing \& Vehicle Communications Symposium, Vol. 1, pp. 766-770, 2015.

\section{AUTHOR'S BIOGRAPHIES}

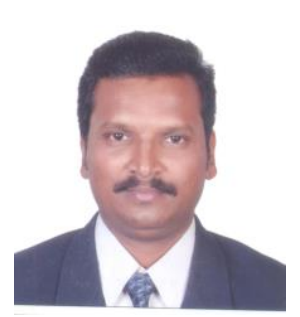

Sadanand R. Inamdar received his Bachelors (B.E.) Degree in Electronics and Communication Engineering from Karnataka University, Dharwad, India in 1994 and Masters (M. Tech.) Degree in Computer Network Eng. from VTU, Belgaum, India in 2004. Currently he is pursuing his $\mathrm{Ph}$. D. from Research Center, CSE, SIT, Tumkur, Karnataka, India. His general research interests are focused on wireless networking. The major topics include wireless Ad hoc networks and quality of service provisioning within these networks. He has published several journal/conference papers in the research area of MANET applications.

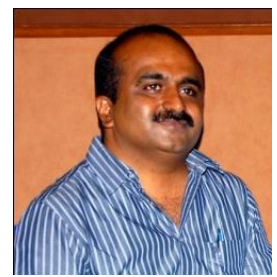

Dr. B. Sathish Babu received his Ph.D. in Protocol Engineering Technology Unit, Department of ECE at Indian Institute of Science, Bangalore. At present he is working as Professor in Computer Science and Engg. Dept., Siddaganga Institute of Technology, Tumkur. His research interests includes Security in mobile communication, Cognitive agents based control solutions for Networks, Grid Computing, Cloud Computing Scheduling and Security Issues, Big Data, Context-aware Trust issues in Ubiquitous Computing, Privacy issues in WSN, and so on. He has published more than 25 international journal/conference papers in his area of research, which includes Elsevier Computer Communications, John Wiley Journal of Security and Communication Networks, InderScience-Journal of Security and its Applications and so on. He has published a book on Mobile and Wireless Network Security (Tata McGrawHill) in the year 2010

Dr. Ravi M. Yadahalli is a distinguished academician and professor of Electronics and Communication Engg. with a career spanning over more than 19 years. He has received $\mathrm{Ph}$. D. (Microwave Electronics) in 2009. He is an educationist \&

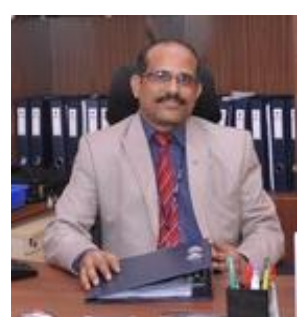
renowned researcher. $\mathrm{He}$ has 16 numbers of publications to his credit both National/International refereed journals of repute. He has guided about 05project/research reports of ME students, and he is guiding 05research scholars for $\mathrm{Ph}$. D degree under VTU, Belgaum, Karnataka, India. Prof. Ravi is reviewer for International Journal of PIER \& JEMWA, USA and also, he has reviewed a number of research papers of National and International Conferences. 